\title{
Study of Structural, Optical and Electrical Properties of Cadmium Telluride Thin Films
}

\author{
Hayder Mohammad Ajeel* \\ Abdul- Hussain Khudair Elttayef
}

\author{
Zainab Turki Hussain, \\ Khalid Mahdi Thajeel
}

\author{
Ministry of Science and Technology-Materials Research Directorate \\ *E-email: asdhayder@yahoo.com
}

\begin{abstract}
$\underline{\text { Abstract }}$
Prepared of the CdTe thin films by thermal evaporation technique in the vacuum of about $3 \times 10^{-3}$ torr. in two concentrations $(x=0.2$ and $x=0.3)$ on glass and silicon substrates. In this study we present the effect of increased concentrations of 0.2 and 0.3 on the structural, optical and electrical properties of The CdTe thin films. The structural properties were study by X-ray diffraction (XRD) and XRF results showed that the films were polycrystalline, optical microscope examination and Atomic Force microscopy (AFM) average grain size $(2 \varepsilon . T V-r) .11) \mathrm{nm}$ for $(\mathrm{X}=0.2$ and $\mathrm{x}=0.3$ ) respectively . The optical properties were characterized by UV-VIS spectroscopy and the electrical properties was study.
\end{abstract}

Keywords: CdTe thin film ;Nano Structural; AFM , Electrical and Effect of concentration.

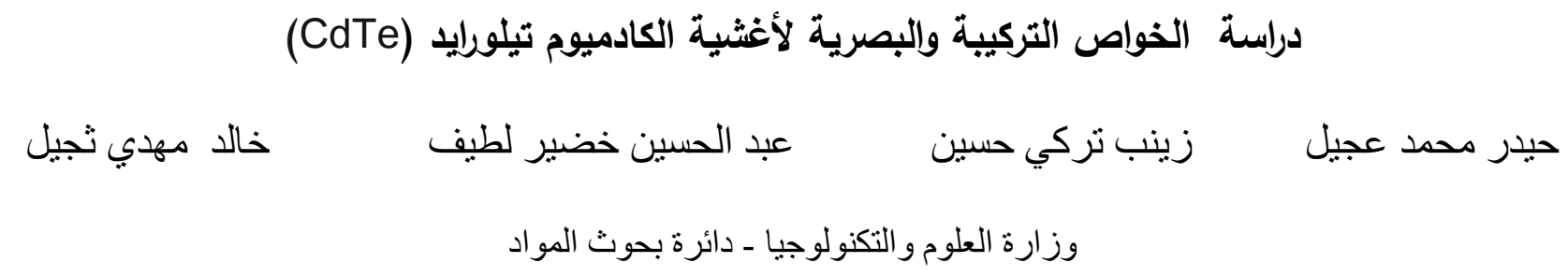

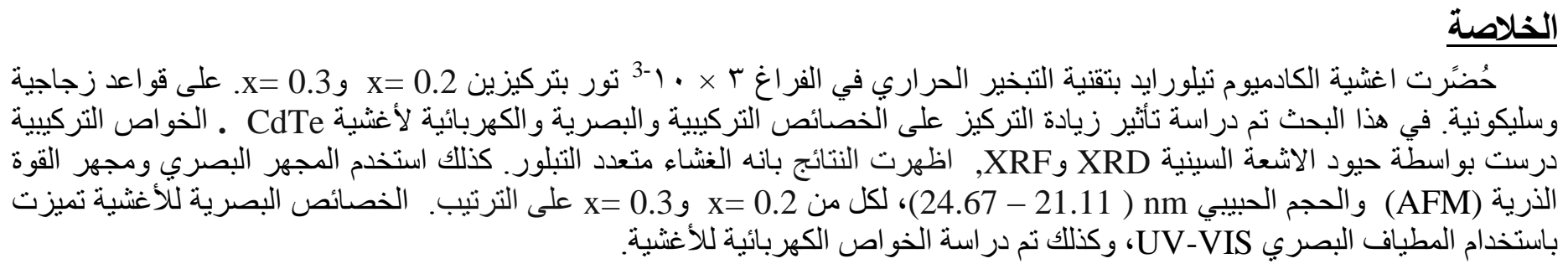

\section{Introduction}

Semi-insulating CdTe semiconductor offers a favorable combination of physical properties that makes it attractive as a high energy radiation detector material for a wide range of applications in imaging systems in security and medicine, industrial process monitoring, nuclear safeguard, astronomy, etc.[1-2].It's semiconductor heterostructures is very important both technologically and scientifically, presenting many applications in optoelectronics and in highly efficiently solar cells [3]. The theoretical solar cell efficiency versus band gap for CdTe and the optical absorption coefficient versus energy for CdTe and other selected photovoltaic materials[4], therefor our proposed detector 
system operates on the same basic principle as a regular CdTe based solar cell .CdTe semiconductor detectors is determined by the charge transport and structural properties of the available crystals [5]. The charge transport properties determine the collection efficiency of free carriers induced by the incident high energy photons and the various sources of noise in the crystals. CdTe surface layer and form a sharp p-n junction [6,7]. Chalcogenide cadmium telluride ( $\mathrm{CdTe}$ ) is recognized as a highly versatile narrow band gap binary compound semiconductor $(\mathrm{Eg}=1.45 \mathrm{eV})$ [8]. The growth of CdTe on silicon is driven mainly by infrared applications. $\mathrm{CdTe} / \mathrm{Si}$ is now being used for the fabrication of megapixel $\mathrm{HgCdTe}$ hybrid infrared focal plane arrays (IRFPAs) [9], purportedly to be used in very large applications in military, space and medical imaging areas for infrared imaging and low-background detection. The basic models that were more often used for the explanation of electrical properties of CdTe were systematized by us in [10]. There are several reports on the growth of CdTe thin film, such as molecular-beam epitaxy (MBE) [11-12], metal organic chemical vapour deposition (MOCVD) [9,10]", "UHV sublimation [11], metal organic vapour phase epitaxy (MOVPE) [12], hot wall epitaxy [13,14], sputtering, thermal evaporation electro deposition, spray pyrolysis and atomic layer epitaxy and chemical bath deposition (CBD). Among various other techniques, thermal evaporation techniques are simple and economical. Recently structural and optical properties of thermally evaporated $\mathrm{CdTe}$ polycrystalline thin films were reported [15]. The goal of the present work is to study the behavior of CdTe thin film structural, optical and electrical properties and effect change the concentration and improve the specifications.

\section{Experimental}

Thin films of CdTe were deposited on glass and silicon n-type substrates by thermal evaporation in a vacuum of about $3 \times 10^{-5}$ torr, using vacuum coating unit. Using CdTe powder with $99.99 \%$ purity with both concentrations $(x=0.2$ and $x=0.3)$. The glass substrates were placed directly above the source at a distance of $20 \mathrm{~cm}$. The glass substrate was cleaned with freshly prepared acetone, detergent solution and distilled water, respectively. Further, the substrate was put in beaker contain on acetone to ultrasonic cleaning before to the evaporation of CdTe for 30 mint. The thickness of thin films were measured by device (MINITEST - 3000) for both concentrations $(x=0.2$ and $x=0.3)$ nearly (2.5 and 3.2) $\mu \mathrm{m}$ respectively.

\section{Results and discussion}

\subsection{X-ray diffraction analysis}

Figures (1 and 2) shows the X-ray diffraction studies of CdTe thin films and powder for concentrations $(x=$ 0.2 and $x=0.3)$ analysis of the thin films indicated the Wurtzite (hexagonal) structure with peaks at $2 \theta=23.8^{\circ}$, $39.37^{\circ}$ and $46.5^{\circ}$ with the orientations (002), (110) and (311), respectively as well as the test results showed that X-rays membranes and powder rich of Te. It was observed that the CdTe crystallites have similar growth on glass substrates along (002) index. XRD spectra are obtained and their respective results have shown a good agreement with standard [X-ray diffraction data file [N 1997 JCPDS prevalent. Japan]. the calculation of grain size by Scherer's formula[16]. The table (1 and 2) shows the structural properties of CdTe thin films.

$\mathrm{D}=\mathrm{K} \lambda / \beta \cos \theta$

D:( G.S) is the grain size

$\mathrm{K}$ : is a constant (0.94)

$\lambda$ : is the wavelength of $\mathrm{Cu} \mathrm{K \alpha}=1.54060\left({ }^{0} \mathrm{~A}\right)$

$\theta$ : is the Bragg's angle

$\beta$ : Full Width at Half Maximum (FWHM)of the preferential plane.

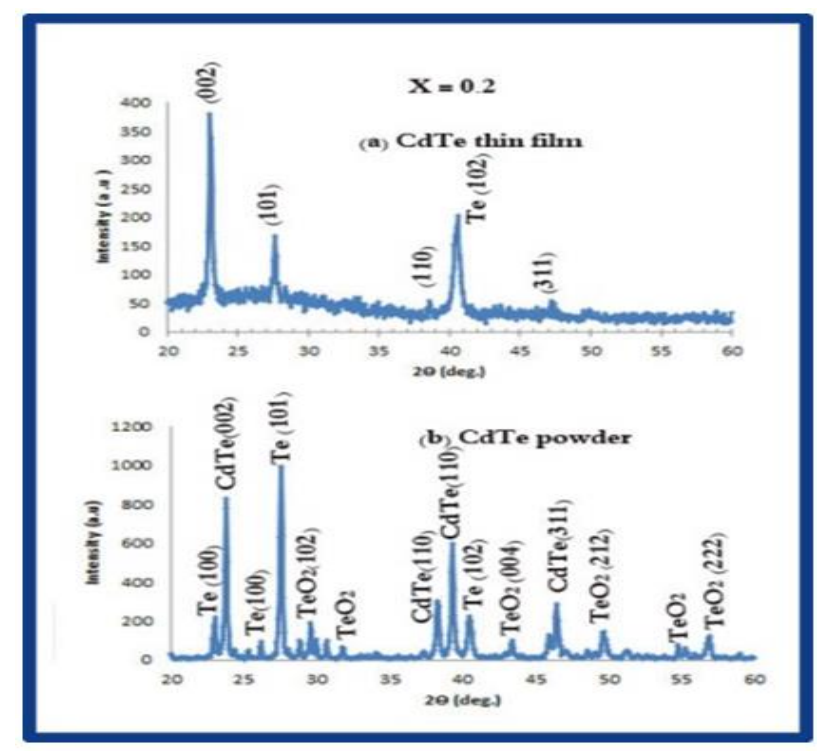

Figure 1 XRD pattern of $\mathrm{Cd} \mathrm{Te}$ thin film : (a) CdTe thin film (b) CdTe powder for $\mathrm{X}=0.2$ 
Table 1. The structural properties of CdTe thin film for $\mathrm{X}=0.2$

\begin{tabular}{|l|c|c|c|c|c|c|}
\hline Sample & $2 \theta$ & $\mathrm{d}\left(\mathrm{A}^{0}\right)$ & $\mathrm{I}(\mathrm{a} . \mathrm{u})$ & FWHM & hkl & G.S(nm) \\
\hline $\mathrm{CdTe}(\mathrm{X}=0.2)$ & 23.75 & 3.74283 & 100 & 0.2826 & 002 & 30.018 \\
\cline { 2 - 7 } & 38.64 & 2.328 & 6 & 0.2000 & 110 & 43.98 \\
\cline { 2 - 7 } & 46.57 & 1.94828 & 3 & 0.1225 & 311 & 73.78 \\
\hline
\end{tabular}

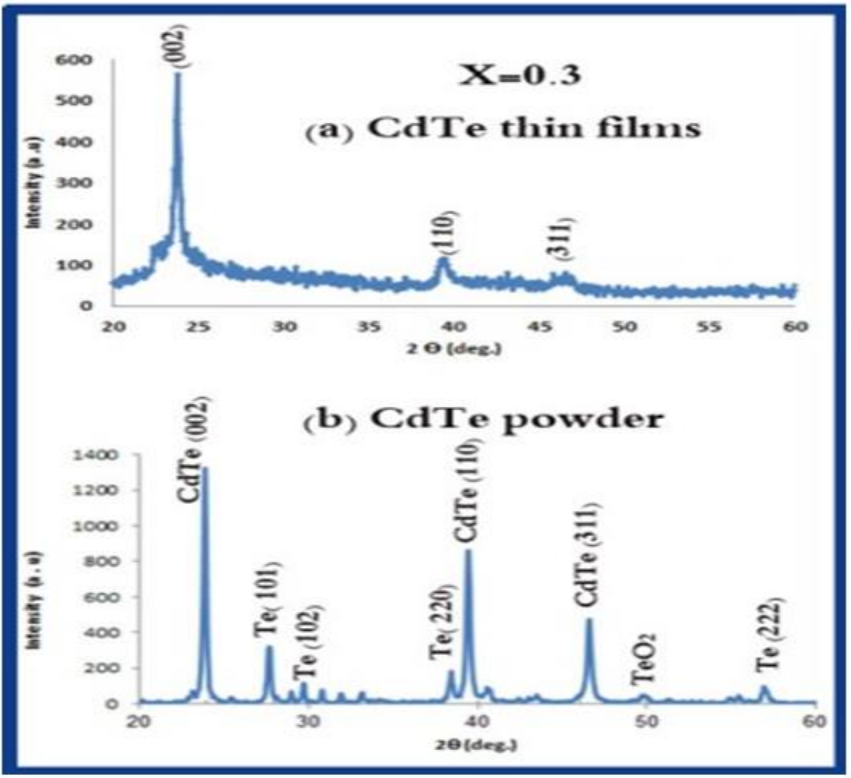

Figure2. XRD pattern of CdTe thin film: (a) CdTe thin film (b) CdTe powder for $\mathrm{X}=0.3$

Table 2. The structural properties of CdTe thin film for $\mathrm{X}=0.3$

\begin{tabular}{|l|c|c|c|c|c|c|}
\hline Sample & $2 \theta$ & $\mathrm{d}\left(\mathrm{A}^{\circ}\right)$ & $\mathrm{I}(\mathrm{a} . \mathrm{u})$ & FWHM & hkl & G.S(nm) \\
\hline \multirow{3}{*}{$\mathrm{CdTe}(\mathrm{X}=0.3)$} & 23.8 & 3.73557 & 100 & 0.3747 & 002 & 22.64 \\
\cline { 2 - 7 } & 39.3755 & 2.28648 & 15 & 0.5925 & 110 & 14.88 \\
\cline { 2 - 7 } & 46.5549 & 1.934 & 7 & 0.35 & 311 & 25.82 \\
\hline
\end{tabular}

In order to quantify the effects of the CdTe thickness on the texture and preferred orientation of the samples, the texture coefficients (TC ) were studied where The Texture coefficient (TC) is used to quantify the preferential orientation of the film deposited at different substrate temperature using the following relation (2)[17].

$\mathrm{TC}=\mathrm{N}(\mathrm{Ii} / \mathrm{Io}) / \Sigma \mathrm{Ni}=1(\mathrm{Ii} / \mathrm{Io}) \ldots \ldots . . .(2)$

where $\mathrm{Ii}$ is the measured intensity, Io is the Joint Committee on Powder Diffraction Standards, (JCPDS) standard intensity and $\mathrm{N}$ is the number of diffraction that peaks. The dislocation density $(\delta)$, defined as the length of dislocation lines per unit volume of the crystal, was evaluated from the formula(3) [18] $\delta=1 / \mathrm{D} 2$

Table 3. Structural parameters of CdTe thin film to $\mathrm{X}=$ 0.2 .

\begin{tabular}{|c|c|c|c|}
\hline sample & $\mathrm{D}(\mathrm{G} . \mathrm{S}) \mathrm{nm}$ & $\delta=1 \mathrm{D}^{2}$ & $\mathrm{TC}$ \\
\hline \multirow{3}{*}{$\mathrm{CdTe}(\mathrm{X}=0.2)$} & 30.018 & $11.1^{*} 10^{-4}$ & 2.999 \\
\cline { 2 - 4 } & 43.98 & $5.169 * 10^{-4}$ & 3 \\
\cline { 2 - 4 } & 73.78 & $1.837 * 10^{-4}$ & 3.006 \\
\hline
\end{tabular}

Table 4. Structural parameters of CdTe thin film to $\mathrm{X}=$ 0.3 .

\begin{tabular}{|c|c|c|c|}
\hline sample & $\mathrm{D}(\mathrm{G} . \mathrm{S}) \mathrm{nm}$ & $\delta=1 / \mathrm{D}^{2}$ & $\mathrm{TC}$ \\
\hline \multirow{3}{*}{$\mathrm{CdTe}(\mathrm{X}=0.3)$} & 22.64 & $19.51^{*} 10^{-4}$ & 3 \\
\cline { 2 - 4 } & 14.88 & $45.16^{*} 10^{-4}$ & 3 \\
\cline { 2 - 4 } & 25.82 & $14.971 * 10^{-4}$ & 3 \\
\hline
\end{tabular}

The calculated dislocation density was found to decrease with increase of grain size as show in tables 3 and 4 . Note that the texture coefficient value for plane (002), (110) and (311) planes constant nearly for both concentrations $(x=0.2$ and $x=0.3)$ that it refer to the thin films good quality.

\subsection{Atomic Force Microscopy (AFM) images}

Figure3. Shows an atomic force microscope images for both concentrations of CdTe thin film ( $X=0.2$ and $X=0.3$ ) to distinguish granular size and crystallization of membrane .

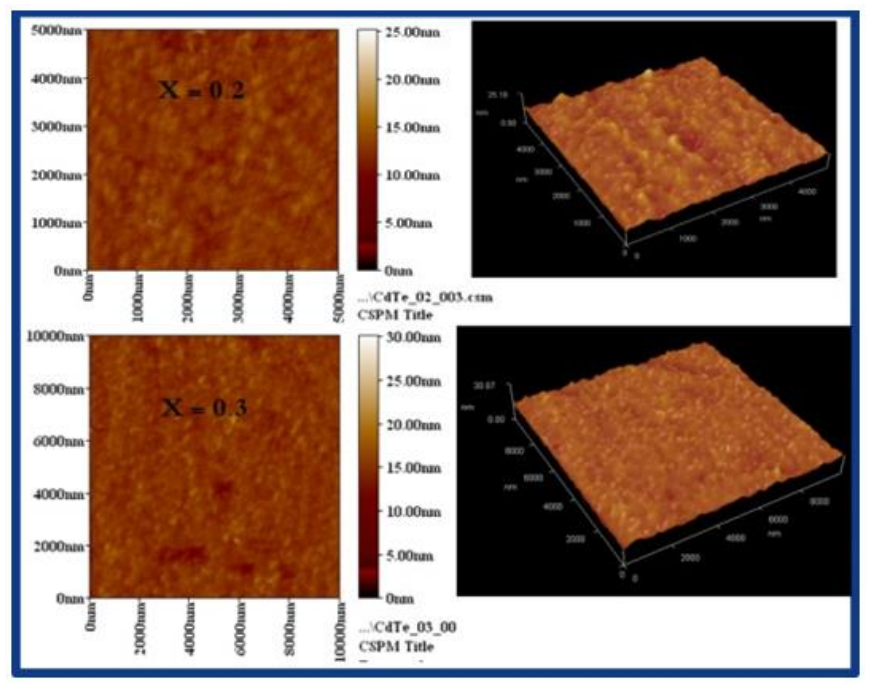

Figure 3. AFM images of CdTe thin film of $X=0.2$ and $\mathrm{X}=0.3$. 


\subsection{The Optical Transmitter Microscopic Examination}

Figure (3: $a$ and $b$ ). Show images for both concentrations of CdTe thin film $(X=0.2$ and $X=0.3)$. Note that the Cdte thin film of $(X=0.3)$ surface more homogeneity and smoothness of the membrane with a CdTe thin film $(X=0.2)$, where we note the disappearance of borders granular holes, which means the disappearance of the defects and surface composition of the Cdte thin film of $(X=0.3)$.

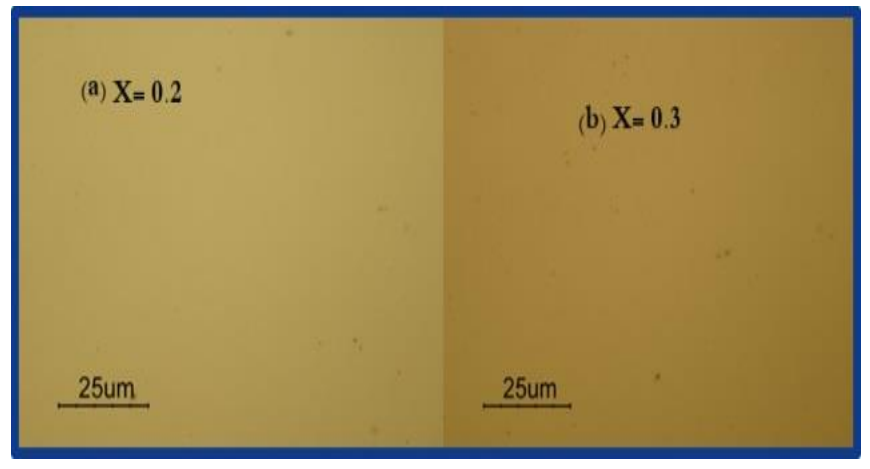

Figure 4. Optical microscope examination images of CdTe thin films (a) $\mathrm{X}=0.2$ and (b) $\mathrm{X}=0.3$.

\section{4- Optical Properties}

The transmittance and absorption spectra of CdTe thin films of both concentrations $(X=0.2$ and $X=0.3)$ were studied in the wavelength range $200-1200 \mathrm{~nm}$ as shown in Figure (5 and 6). The absorption increases with increase in the concentration .While The transmittance decreases with increase the concentration .The method used to determine the value of energy gap $(\mathrm{Eg})$ in volves plotting a graph of $(\alpha \mathrm{h} v)^{\mathrm{n}}$ versus $(\mathrm{h} v)$. The photon energy $(h v)$, obtained and $n=1 / 2$ was obtained by others [19], A a constant (independent from $v$ ) and absorption coefficient $(\alpha)$ for direct optical transition are related by the following equation (4) [20]. Energy gap increases with increasing concentrations as show in figure7, this can be explained as due to the presence of defects in amorphous materials [21].

$\alpha h \nu=A\left(h v-E_{g}\right)^{n}$

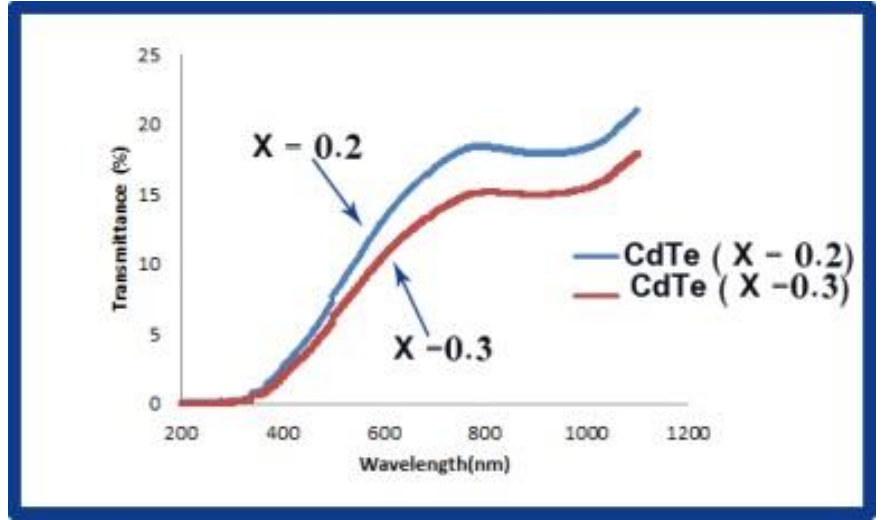

Figure 5. Transmittance spectra of CdTe thin films of both $t$ concentrations $(X=0.2$ and $X=0.3)$ deposited on the glasses.

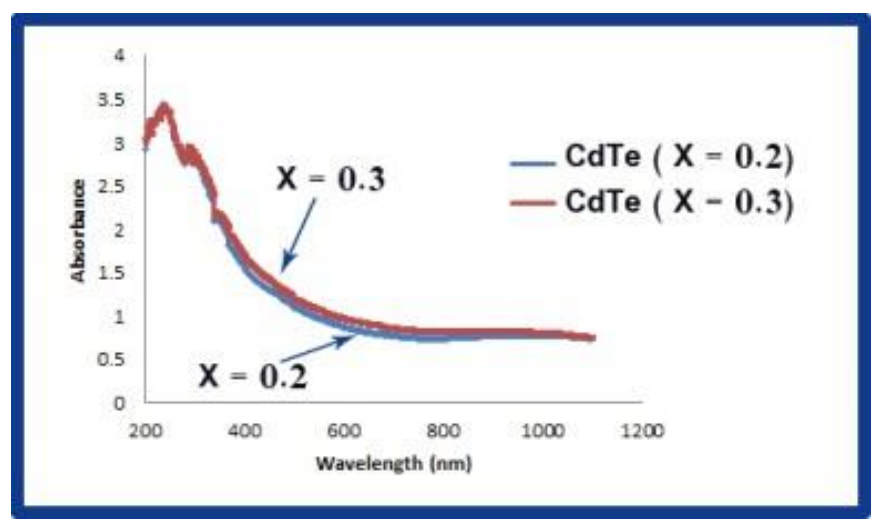

Figure 6. Absorbance spectra of CdTe thin films of both $t$ concentrations $(X=0.2$ and $X=0.3)$ deposited on the glasses

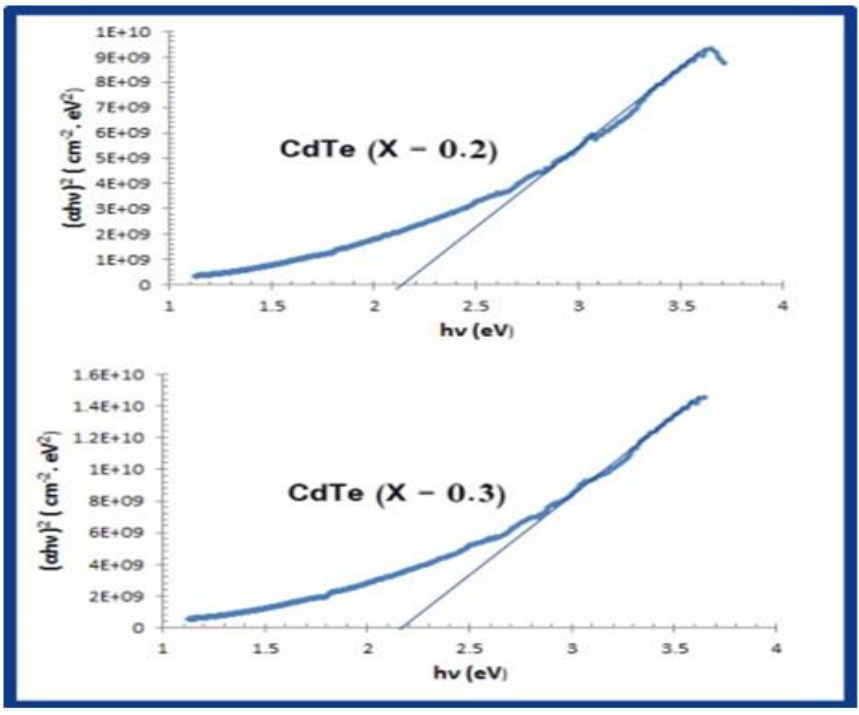

Figure 6. Energy gap of CdTe thin films of both $t$ concentrations $(X=0.2$ and $X=0.3)$ deposited on the glasses. 
It is observed that increase in t concentrations of CdTe ( $\mathrm{X}=0.2$ and $\mathrm{X}=0.3$ ) causes a slight increase in optical band gap from $2.11 \mathrm{eV}$ to $2.18 \mathrm{eV}$ respectively as show in figure 6 .

\section{5- Electrical conductivity and}

The d.c conductivity $(\sigma)$ has been studied using the electrical circuit which was consisted of oven and avometer. The variation of conductivity with temperature (T) is main tool in investigation properties of semiconductors. It is very useful to determine the extrinsic range the activation energies of impurity centers and in the intrinsic range the main energy gap. D.c conductivity $(\sigma)$ of samples obtained using equation (5) [22].

$\sigma=\mathrm{L} / \mathrm{R} . \mathrm{t}$

where $\mathrm{L}$ is distance separated the electrodes, $\mathrm{R}$ is resistance of film. Then the activation energy (Ea) can be calculated from the equation(5) [23]:

$\sigma=\sigma o \exp (\mathrm{Ea} / \mathrm{kBT}) \ldots . .(5)$

where $\mathrm{T}$ is absolute temperature, $\sigma 0$ is minimum metallic conductivity and $\mathrm{kB}$ is Boltazmann constant.

Then the conductivity of the films was determined by using the equation:-

$\sigma=1 / \rho \ldots \ldots(6)$

The resistivity $(\rho)$ of the films is calculated by using the following equation (7) [24]:-

$\rho=$ R.A $/ \mathrm{L} \ldots \ldots . .(7)$

Where, $\mathrm{R}$ : is the resistance.

A: is the area of the film (W.t).

$\mathrm{W}$ : is the width of the electrode.

$\mathrm{t}$ : is the films thickness.

$\mathrm{L}$ : is the distance between the electrodes

The d.c. conductivity for (CdTe) thin films with different thickness has been studied as a function of (103/T) within thermal range (40-85) oC as in figure (7). Activation energies (Ea1, Ea2and $\mathrm{Ea}$ ) for both concentrations $(X=0.2$ and $X=0.3)$ respectively were calculated from $\ln \sigma$ vs $1 / \mathrm{T} p$ lots for CdTe films deposited on silicon type $-\mathrm{n}$ in the temperature (4085)oC.

The overall conductivity increases with increase of film concentrations, increase of concentrations lead to increases in thickness. The increase in conductivity due to increasing thickness may be attributed to the increasing number of oxygen vacancies present in the sample, in the other word, the electrical conductivity decreases with increasing temperature. Also, from Figure. 7 it can be see that the value of electrical conductivity tends to increase with increasing in film concentrations, while The resistivity increases with increasing temperature, but it decrease with increasing in film concentrations. We note activation energy has two values of concentration $\mathrm{X}=0.2$ (Ea1 $=0.0194$ and $\mathrm{Ea} 2=0.00294) \mathrm{eV}$, whereas activation energy of concentration $\mathrm{X}=0.3$ has only one $\mathrm{Ea}=0.0155 \mathrm{eV}$. The decrease in activation energy with increasing film concentration may be due to the change in structural parameters, improvement in crystallite and grain size, decrease in the grain boundaries and removal of some impurities [25].

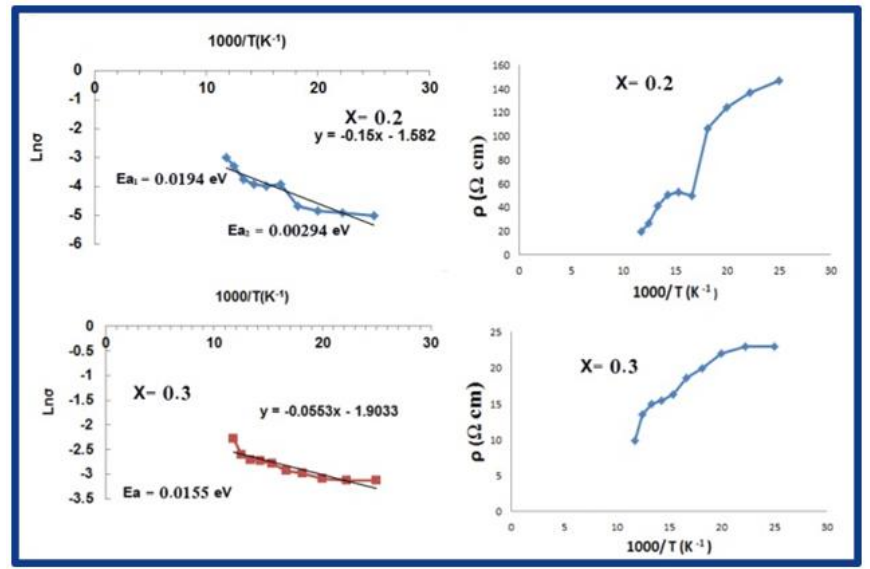

Figure 7. Plots of conductivity and resistivity vs $\left(10^{3} / \mathrm{T}\right)$ within thermal range $(40-85)^{\circ} \mathrm{C}$ of both concentrations $(\mathrm{X}=0.2$ and $\mathrm{X}=0.3$ ) of CdTe thin films deposited on silicon type-n.

\section{6- Conclusions}

1- CdTe thin films have been thermally evaporation deposited onto glass and silicon substrates with two concentrations $(X=0.2$ and $X=0.3)$. The thickness of the films was varied from $(2.5$ and 3.2$) \mu \mathrm{m}$ respectively. XRD analysis has shown that all investigated samples are polycrystalline in nature having a hexagonal structure with preferential orientation along (002) plane, AFM images it was found that the mean grain size and root mean square roughness of films surface increased as the film concentrations increased. 
2 - The Optical studies carried out on the films reveals that the film deposited in higher concentrations are of low transmittance and high absorbance nature. It also shows that as the concentrations increases band gap increases.

3-We studied in detail the influence of concentrations on the electrical conductivity of CdTe thin films. electrical conductivity decreasing with increasing annealing temperature and it increase with increase concentrations, while activation energies shows as decreasing with increasing concentrations.

\section{$\underline{\text { References }}$}

[1] Hage-Ali, M. and Siffert, P., "Semiconductors for room temperature nuclear detector applications" in: Schlesinger, T.E. and James, R.B. (Eds.) Semiconductor and Semimetals, Vol. 43, Academic Press, San Diego, (1995).

[2] Yadav, J. S., Savitri, S. and Malkar, J. P., "Near room temperature $\mathrm{X}$-ray and $\gamma$-ray spectroscopic detectors for future space experiments," Nucl. Instrum. Meth. A, 552, 399-408 (2005).

[3] R. Hull, J.C. Bean, Adv. Mater. 3 (1991) 139.

[4] Based on Rothwarf A, Boer K, Prog. Solid. State Chem. 10, 71-102 (1975).

[5] Acrorad Co, Ltd., 13-23 Suzaki, Gushikawa, Okinawa 904-2234, Japan, http://www.acrorad.co.jp.

[6] Gnatyuk, V. A., Aoki, T., Hatanaka, Y. and Vlasenko, O. I. "Defect formation in CdTe in the act of laser-induced doping and application to the manufacturing nuclear radiation detectors," Phys. Stat. Sol. (c) 3, 1221-1224 (2006).

[7] Gnatyuk, V. A., Aoki, T. and Hatanaka, Y. "Laserinduced shock wave stimulated doping of CdTe crystals," Appl. Phys. Lett. 88, 242111-1242111-3, 2006.

[8] J.I. Pankove, Optical Processes in Semiconductors, Dover, New York, 1975

[9] O.K. Wu, T.J. de Lyon, R.D. Rajavel, J.E. Jensen, in: P. Capper (Ed.), Narrow-gap II-VI Compounds for Optoelectronic and Electromagnetic Applications, Chapman \& Hall, London UK, 1997, p. 971 (Chapter 4).

[10] V.V. Kosyak, A.S. Opanasyuk, I.Yu. Protsenko. Point defects ensemble in CdTe single crystals

[11] M. S. Han, T. W. Kang, J.H. Leem, M.H. Lee, K.J. Kim, T.W. Kim, J. Appl. Phys.82, 6012 (1997).
[12] H. Ebe, T. Okamoto, H. Nishino, T. Saito, Y. Nishijima, M .Uchikoshi, M. Nagashima, H. Wada, J. Electron. Mater. 25, 1358 (1996).

[13] R. Korenstein, P. Madison, P. Hallock, J. Vac. Sci. Technol. B 10, 1370 (1992).

[14] H. Tatsuoka, H. Kuwabara, Y. Nakanishi, H. Fujiyasu, J. Cryst.Growth 129, 686 (1993).

[15] Lalitha S, Karazhanov S Zh, Ravindran P, Senthilarasu S, Sathyamoorthy $\mathrm{R}$ and Janabergenov J 2007 Physica B 387227

[16] Th.H.DE.Keijser, et al., J. Appl. Cryst., 15(1982)308-314.

[17] Hadouda H, Pouzet J, Bernede J C and Barreau A 1995 Mat. Chem. Phys. 42291

[18] G. B. Williamson, R. E.Smallman, III. Philos. Mag. 1, 34 (1956).

[19] N.A. Hegab, M. Fadel, M. M. El -Samanoudy, J. Mater. Sci. 30, 5461 (1995).

[20] A. Goswami, Thin Film Fundamentals (New Age International (P) Ltd., (1996)) P.No. 421 [21] J. I. Pankove "Optical Processes in Semiconductors", Prentice-Hall, New Jersey,(1971).

[22] S. Sali1, M. Boumaour and R. Tala-Ighil, "Preparation and characteristic of low resistive zinc oxide thin films using chemical spray technique for solar cells application, the effect of thickness and temperature substrate" Revue des Energies Renouvelables, CICME'08 Sousse, 201 (2008).

[23] N.F.Mott and, E.A.Davis, "Electronic processes in non-crystalline materials" .Second edition, 32 (1993).

[24] William, D. Callister, (2003) "M aterials Science and Engineering, an Introduction", $6^{\text {th }}$ edition, John Wiley \& Sons, Inc.

[25]R. B. Kale, C. D. Lokhande, Semicond. Sci. Technol. 20, 1 (2005). 